\title{
Geochemical variation of soil-gas composition for fault trace and earthquake precursory studies along the Hsincheng fault in NW Taiwan
}

\author{
Vivek Walia $^{\text {a,* }}$, Tsanyao Frank Yang ${ }^{\text {b }}$, Wei-Li Hong ${ }^{\text {, }}$, Shih-Jung Lin ${ }^{\text {a }}$, Ching-Chou Fu ${ }^{\text {, }}$, \\ Kuo-Liang Wen ${ }^{\mathrm{a}, \mathrm{c}}$, Cheng-Hong Chen ${ }^{\mathrm{b}}$ \\ a National Center for Research on Earthquake Engineering, National Applied Research Laboratories, Taipei 106, Taiwan \\ ${ }^{\mathrm{b}}$ Department of Geosciences, National Taiwan University, Taipei 106, Taiwan \\ ${ }^{\mathrm{c}}$ Department of Earth Sciences and Institute of Geophysics, National Central University, Jhongli 32054, Taiwan
}

\section{A R T I C L E I N F O}

\section{Article history:}

Received 4 June 2008

Received in revised form

5 June 2009

Accepted 3 July 2009

\section{Keywords:}

Soil-gas

Fault

Earthquake

Helium

Radon

Carrier gases

\begin{abstract}
A B S T R A C T
The present study is proposed to investigate geochemical variations of soil-gas composition in the vicinity of the geologic fault zone of Hsincheng in the Hsinchu area of Taiwan. Soil-gas surveys have been conducted across the Hsincheng fault, to look for the degassing pattern of this fault system. During the surveys, soil-gas samples were collected along traverses crossing the observed structures. The collected soil-gas samples were analysed for $\mathrm{He}, \mathrm{Rn}, \mathrm{CO}_{2}, \mathrm{CH}_{4}, \mathrm{Ar}, \mathrm{O}_{2}$ and $\mathrm{N}_{2}$. The data analysis clearly reveals anomalous values along the fault. Before selecting a monitoring site, the occurrence of deeper gas emanation was investigated by the soil-gas surveys and followed by continuous monitoring of some selected sites with respect to tectonic activity to check the sensitivity of the sites. A site was selected for long term monitoring on the basis of coexistence of high concentration of helium, radon and carrier gases and sensitivity towards the tectonic activity in the region. A continuous monitoring station was established at Hsinchu National Industrial Science Park (HNISP) in October 2005. Preliminary results of the monitoring station have shown possible precursory signals for some earthquake events.
\end{abstract}

(c) 2009 Elsevier Ltd. All rights reserved.

\section{Introduction}

Soil-gas variations due to change in stress related to seismotectonic activity are well documented and are used extensively for seismotectonic studies, including fault tracing and seismic surveillance as a precursor. Several gases with different origins and contrasting behaviours in soil have been documented for detecting a fracture network and characterizing its extension and shape (Fu et al., 2005; Toutain and Baubron, 1999; Ciotoli et al., 1998; Walia et al., 2005a). The composition and distribution of gases in the soil pore are affected by surface features such as pedological, biogenic and meteorological factors. However, these are thought to have a subordinated effect on gas leakage from deep fault-related features (Toutain and Baubron, 1999; Fu et al., 2005). It is commonly accepted that in the faultrelated features gas migration is supported by advection. However, several phenomena like variation of groundwater table, meteorological changes, soil porosity/permeability or degree of fracturing, etc. may alter original gas concentrations for a single gas. This problem can be reduced by studying a number of soil-gases with different origins and contrasting behaviours; collection of a large number of samples and the use of an

\footnotetext{
* Corresponding author. Tel.: +88626630 0575; fax: +88626630 0858.

E-mail addresses: vivekwalia@rediffmail.com, walia@ncree.org.tw (V. Walia).
}

appropriate statistical processing of the collected data can lead soil-gas method as a powerful tool for geological and tectonic investigations.

Radon, helium and carrier gases (viz.) carbon dioxide, nitrogen, methane, etc., are recognized as potential tracers of fault systems (Al-Taminmi and Abumurad, 2001; Banwell and Parizek, 1988; Walia et al., 2008; Fu et al., 2008) and are commonly used as precursors for earthquake and volcanic activity studies (Virk et al., 2001; Walia et al., 2005b, 2006; Yang et al., 2005, 2006). Therefore, we focused on these soil-gas concentrations for the present study. As no trace of methane is found in the investigated area, further discussion of methane as an indicator for this study has been ruled out.

Radon, due to its short half-life, displays poor intrinsic mobility (diffusion coefficient of $0.12 \mathrm{~cm}^{2} / \mathrm{s}$ ) and therefore in a diffusive system it obviously comes from a short distance below the measuring instrument. Deep origin signals can be observed only if convection/advection occurs, radon being carried upward to soil surface by a rising gas/water column (Etiope and Martinelli, 2002; Yang et al., 2003). In general, radon activities increase with the increase in the flow rate of the soil-gas, as the increased flow rate increases gas velocity which gives ${ }^{222} \mathrm{Rn}$ less time to decay and more extraction from the fissure walls. However, for higher flows, dilution of radon by carrier fluids/gases may occur ((Shapiro et al., 1982; Heinicke et al., 1992; Etiope and Martinelli, 2002). 
Helium is characterized by its high mobility and low solubility in water. Due to these features helium shows highly diffusive character with diffusion coefficient $\left(1.68 \mathrm{~cm}^{2} / \mathrm{s}\right)$, about ten times higher than those of $\mathrm{N}_{2}, \mathrm{O}_{2}$ and $\mathrm{CO}_{2}$. Helium has a low and constant concentration of $5.239 \pm 0.004 \mathrm{ppm}$ in air (Roberts et al., 1975). Due to its characteristics and deep origin with respect to radon, helium appears as a powerful pathfinder for crustal discontinuities, faults and fractures (Pinault and Baubron, 1997; Ciotoli et al., 1998).

Both radon and helium are decay products of uranium/thorium decay series. The advective movement of radon and helium must be referenced to carrier gases (viz. $\mathrm{CO}_{2}, \mathrm{~N}_{2}$ ) which form large domains that can carry these rare gases towards surface. Carbon dioxide is a well defined carrier gas for noble gases such as radon and helium, which are unable to reach the surface due to their low mobilities and very small quantities, respectively. Carbon dioxide has several sources: the mantle, metamorphism of carbonatebearing rocks, decomposition of organic materials and surficial biological activity (Irwin and Barnes, 1980). Carbon dioxide is a mixture of some of these sources (Fu et al., 2005). High $\mathrm{CO}_{2}$ fluxes can be correlated with both high heat flux areas in fault zones (associated with active and inactive volcanism) and limited areas of deep fracturing (carbon emitting from the mantle and from decarbonation processes, with possible mixing of these two sources). $\mathrm{CO}_{2}$ flux may indicate the areas having high pore pressure at deep and therefore, may serve to identify potential seismic regions (Irwin and Barnes, 1980; Sugisaki et al., 1980, 1983; Baubron et al., 1990, 1991), as well as seismic and volcanic monitoring (Shapiro et al., 1982; Toutain et al., 1992; Rahn et al., 1996).

Nitrogen can also act as a good carrier gas for noble gases like radon and helium, and has been detected in soil and water. Nitrogen has several sources and can be affected by various physical, chemical and biological processes.

The present study aims to check the efficiency of soil-gas technique and to determine a possible connection between eventual soil-gas anomalies not only for radon and helium but also for carrier soil-gases which might be related to the fault systems of Hsincheng fault (Fig. 1) in the Hsinchu area of NW Taiwan. Continuous monitoring can be helpful for understanding of the regional seismic activity and stress build up of the fault system. This further can be helpful for continuous monitoring of regional seismic activity and stress build up of the fault system.

\section{Geological setting}

Taiwan is located in a pivotal position in world's seismic map as it is settled along the collision boundary between the Eurasian and Philippine Sea plates which makes the island vulnerable by high tectonic activity with a number of active faults. Hsinchu area located in the NW Taiwan has great importance in Taiwan's economy due to the presence of a leading Industrial Science Park named Hsinchu National Industrial Science Park (HNISP). In Hsinchu area, two active faults, the Hsinchu and the Hsincheng, have been observed. Hsincheng fault is a low angle $\left(30-40^{\circ}\right)$ thrust fault which extends $28 \mathrm{~km}$ from north bank of Chung-Kang river to the south bank of Feng-Shan river. The fault system could be divided into two sections: southern section (Chu-Dun hill area) whose detachment surface is between Ching-Shui formation and Cho-Lan formation, and northern section (Fei-Fong hill area) whose detachment surface is inside the Tou-Ke-Shan formation. Based on trench observation and paleoseismic study in this area, the slip rate of Hsincheng fault is about $0.7-1.6 \mathrm{~mm} / \mathrm{yr}$; the recurrence interval is about $2 \mathrm{ka}$, and the latest slip record was ca. 300 years ago. Hsincheng fault has been also classified as an active fault by the Central Geological Survey, MOEA (Lin et al., 2000).

Fault trace of southern section has been defined by Digital Elevation Model (DTM) observations, seismic data, borehole drillings, trench observation, and by a number of geophysical or geological studies in this area (Shih, 1999; Lin et al., 2000). Unfortunately, because of the poor conditions in the northern bank of Feng-Shan river, the fault trace of northern section of Hsin-Cheng fault could not be clearly defined.

There are some other northeast-southwest faults and anticline systems in this area: Hsinchu fault, Pao-Shan anticline and ChingTsau-Hu anticline (Fig. 1). Scarps of the Hsincheng and Hsinchu faults and enigmatic intervening scarps cut and deform the narrow fluvial terraces at the south of the river. The overall trend of the fault system is east-west. Besides these fault and anticline systems, some northwest-southeast ward fractures have also been found in this area. This implies that there must be at least

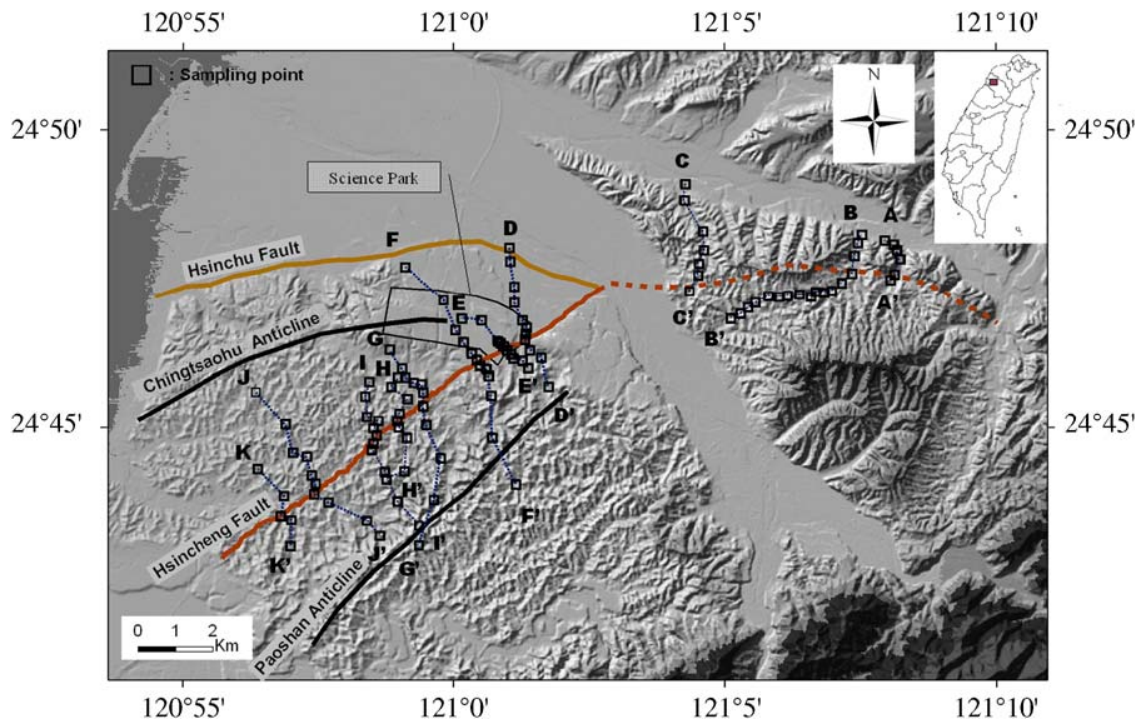

Fig. 1. Distribution of different profiles along Hsincheng fault in Hsinchu area, dotted line represents probable extension of the fault. 
two opposite stress directions in this area which makes the fault systems much more complicated.

\section{Sampling procedure and monitoring station setup}

To carry out the investigations in the soil-gas, a number of transverse profile surveys have been conducted across the probable fault extensions of the Hsincheng fault. During these soil-gas surveys, samples were collected along the traverses crossing the observed structures and analysed for radon, helium, carbon dioxide, methane, argon, oxygen and nitrogen.

In soils, gases were generally sampled at depths of $0.7-1.0 \mathrm{~m}$ using steel probes. For this purpose, a hollow steel probe of $3 \mathrm{~cm}$ in diameter and $130 \mathrm{~cm}$ of length was selected and a disposable sharp awl was attached at the bottom of steel probe. This steel probe was emplaced into a ground at the depth of about $0.8-1.0 \mathrm{~m}$ by hammer pounding. A thin solid billet (punching wire) was used to displace the tip and allowed the lower end of the probe to be in contact with soil-surface at the required depth. A hand-pump, through a specially designed rubber tube (with two filters: one is for dust and another one is for mist) connected with the hollow steel probe, was used to collect gas into sample bag (Fig. 2). Whenever flux rate was good enough the hand pump was replaced by alpha-pump (an automatic pump having pumping rate of $1 \mathrm{l} / \mathrm{min}$ ) to collect soil-gas in vacuum created sample bags having capacity of 1 and 31 , respectively. Before collecting the soil-gas in sample bags the tube and the probe were flushed for the air which might be present by pumping for about $1 \mathrm{~min}$.

Sample bags used for collecting soil-gas are Tedlar standard sample bags (manufactured by SKC) which utilize a lightweight, patented single fitting of inert polypropylene that combines the hose/valve and the septum holder into one compact fitting for 11 bags, whereas for 31 bags, there are two fittings of inter polypropylene that combines the hose/valve and the septum holder which allow the sample bag to be used in closed circuit for radon analysis. The sample bottle, which is made of potassium glass to preserve helium gas from escaping by diffusion, is used for further helium isotope analysis.

The collected soil-gas in $1 \mathrm{~L}$ sample bag was analysed for $\mathrm{He}$, $\mathrm{N}_{2}, \mathrm{CO}_{2}, \mathrm{CH}_{4}, \mathrm{Ar}$ and $\mathrm{O}_{2}$ using helium detector ASM100HDS (ALCATEL) and Micro Gas Chromatography CP4900 (VARIAN),

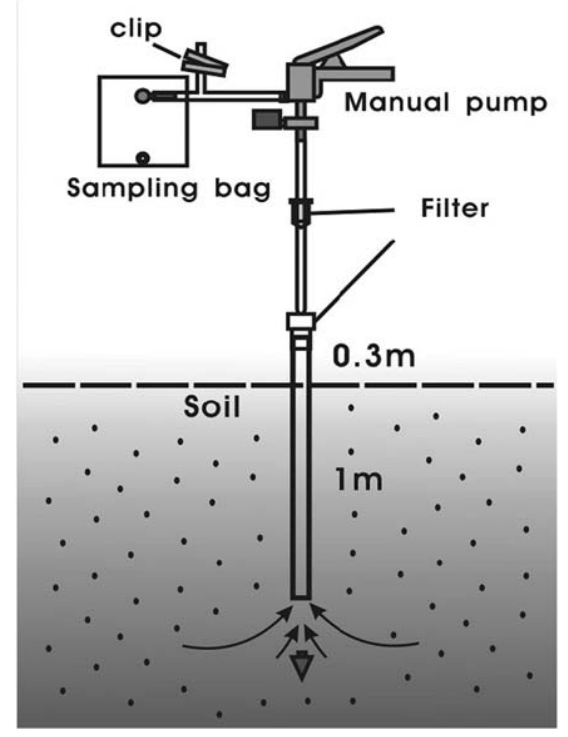

Fig. 2. Sampling scheme used for collecting soil-gas samples. respectively. The soil-gas collected in 31 sample bag was analysed for radon using Radon detector RTM 2100 manufactured by SARAD.

To build a monitoring station, reconstructions were done of all the selected points by digging holes of $2 \mathrm{~m}$ and by casing these holes with PVC pipes. At the bottom of PVC pipe a fine mesh is attached to avoid any unwanted materials to enter the pipe. The PVC sheet is put on all the sides of the PVC pipe at bottom covering about $1 \mathrm{~m}$ on all sides; this avoids the rain water to get in the hole. Some pebbles are also put at the bottom to reduce the meteorological effects before filling the sides of the holes. After continuous weekly monitoring, one point was selected for the setting of continuous monitoring station and housing was done on it.

\section{Results and discussion}

In order to recognise the fault trace of the Hsincheng fault in Hsinchu area, during our investigation soil-gas surveys were conducted, especially in National Science Industrial Park. Soil-gas surveys were performed across 11 profiles (Fig. 1) and more than 118 samples were collected for ${ }^{4} \mathrm{He}, \mathrm{CO}_{2}, \mathrm{~N}_{2}, \mathrm{CH}_{4}, \mathrm{Ar}, \mathrm{O}_{2}$, etc. (using 11 bags) and 64 samples for ${ }^{222} \mathrm{Rn}$ (using 31 bags) analyses, covering an area of about $30 \mathrm{~km}^{2}$ along the fault system. The surveys were repeated on some profiles to re-check the trends and it was found that the trends were reproducible.

The recorded radon, helium, carbon dioxide and nitrogen concentrations show large spatial variations along the fault and the detection of anomaly has to be defined prior to the analyses. To identify the anomalies of various gases, different statistical methods were applied by different authors in the past (Klusman, 1993; Lepeltier, 1969; Guerra and Lombardi, 2001; Baubron et al., 2002; Fu et al., 2005; Walia et al., 2005a). The very common practice of considering the mean plus standard deviation as being anomaly is generally accepted in soil-gas studies and found to be convenient for soil-gas data interpretations (Guerra and Lombardi, 2001; Fu et al., 2005; Walia et al., 2005a). In statistical threshold value of gas anomalies was fixed at mean plus one standard deviation $(1 \sigma)$ for each profile and all the gas species. To define the mean and standard deviation, anomalously high and low values, which may cause unnecessary high deviation and perturb the real anomalies, have been neglected. The soil anomalies cannot be absolutely fixed for the whole data set with regard to complex origins and migration of different gas species. Soil-gas composition and distribution of gases in the soil atmosphere are affected by surface features such as pedological and meteorological parameters can cause big deviation in values. In order to minimize the influences of these parameters sampling along each profile was completed in a single day and under similar conditions. So, in our context deviation in spatial distribution of gas species are most likely due to presence of tectonic features present the area and not due to meteorological or other parameters. Hence, mean plus one standard deviation $(1 \sigma)$ good enough to define threshold value of gas anomalies.

The spatial distribution of ${ }^{4} \mathrm{He},{ }^{222} \mathrm{Rn}, \mathrm{CO}_{2}$ and $\mathrm{N}_{2}$ concentrations along the each profile has been plotted and shown in Fig. 3 after normalizing data for the profiles by dividing for each soil-gas component concentration by its maximum value along the profile and thereafter multiplying by ten. The studied area has shown wide range of variation in concentration for all these gases. Soil-gas radon concentration varies from $0.7 \pm 0.1$ to $40.6 \pm 0.7 \mathrm{kBq} / \mathrm{m}^{3}$ whereas the helium concentration varies from 5.16 to $5.94 \mathrm{ppm}$. The carrier gases show variation from $0.00 \%$ to $13.84 \%$ and $74.08 \%$ to $92.23 \%$ for $\mathrm{CO}_{2}$ and $\mathrm{N}_{2}$, respectively. Maximum number of samples (i.e. 17) were collected along the 
B-B' and E-E' profiles whereas minimum number (i.e. five) pertains to the profile $\mathrm{K}-\mathrm{K}^{\prime}$ (Fig. $3 \mathrm{~b}$, e and $\mathrm{k}$ ).

All profiles were supposed to exhibit anomalies where the fault was expected to appear. The $A-A^{\prime}, B-B^{\prime}$ and $C-C^{\prime}$ profiles have been taken along northern end of Hsincheng fault, where the fault shows its probable extension (Fig. 1). Along these profiles radon data were not available due to some instrumental problems. The profile $\mathrm{E}-\mathrm{E}^{\prime}$ is one of the most important profile crossing the fault at the Hsinchu National Industrial Science Park (HNISP) (Fig. 1). Along this profile maximum number of anomalies was recorded in the gas species of ${ }^{4} \mathrm{He},{ }^{222} \mathrm{Rn}, \mathrm{CO}_{2}$ and $\mathrm{N}_{2}$ (Fig. 3e). Also along this profile ${ }^{4} \mathrm{He}$ and $\mathrm{N}_{2}$ show highest of $5.94 \mathrm{ppm}$ and $92.24 \%$, respectively, at point E4 (Fig. 3e). These values were not only the highest points for the profile, but with respect to the whole survey. ${ }^{222} \mathrm{Rn}$ concentrations show highest values of $40.6 \pm 0.7 \mathrm{kBq} / \mathrm{m}^{3}$ at the point E16 followed by a

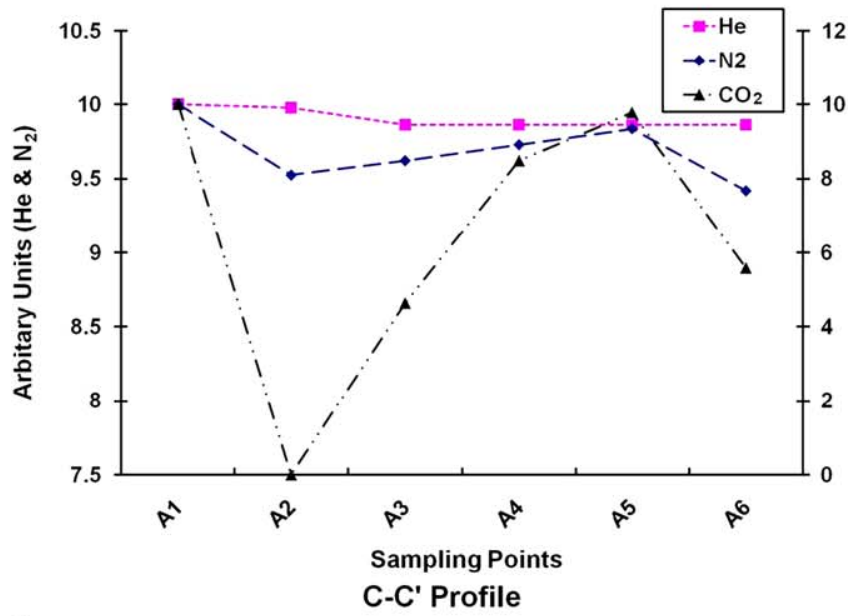

C

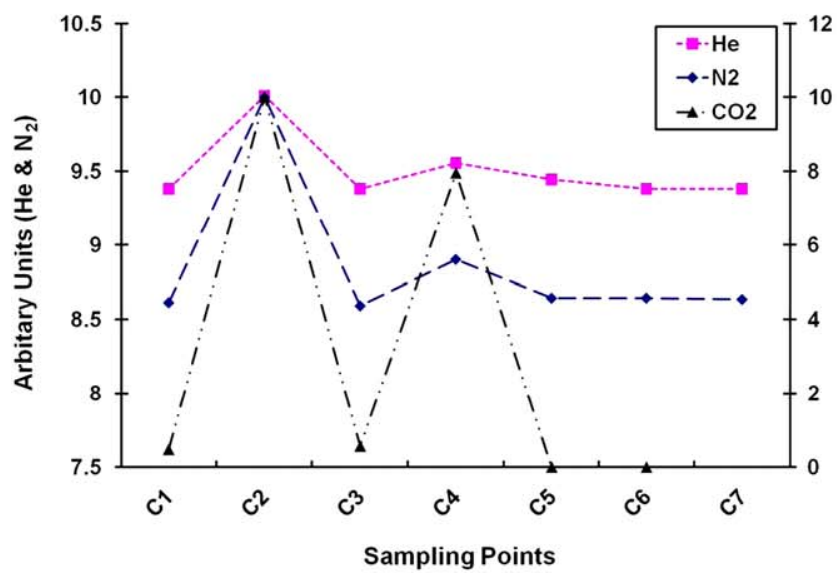

e

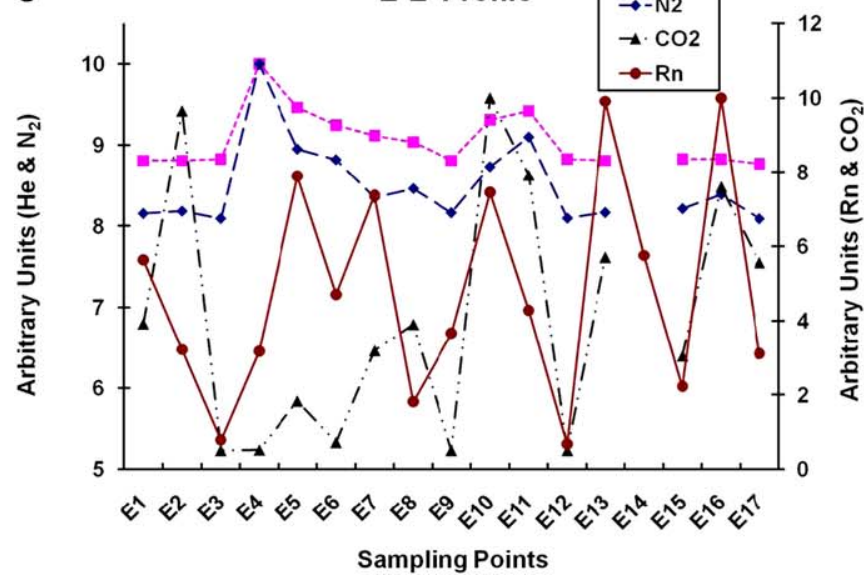

b

B-B' Profile

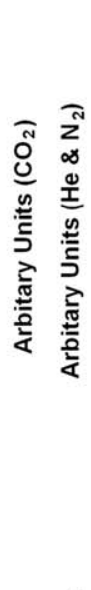

d

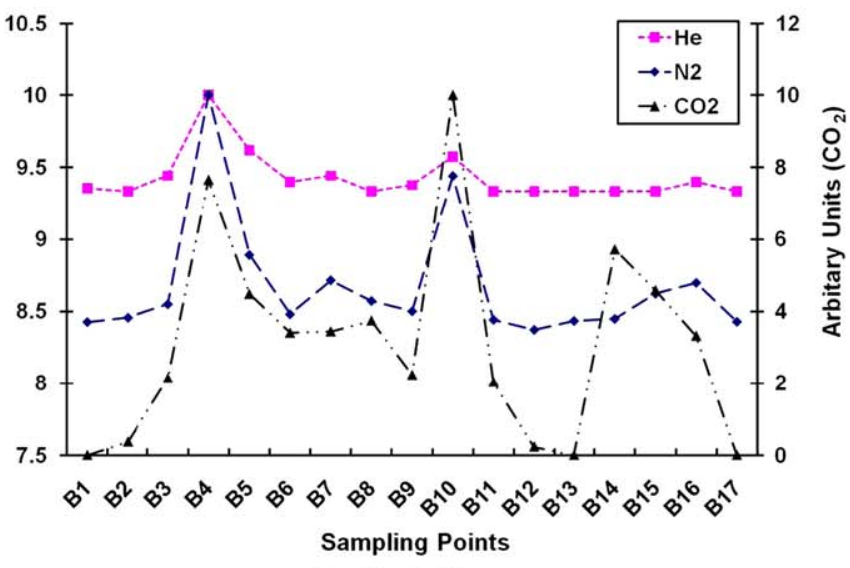

Profile D-D'
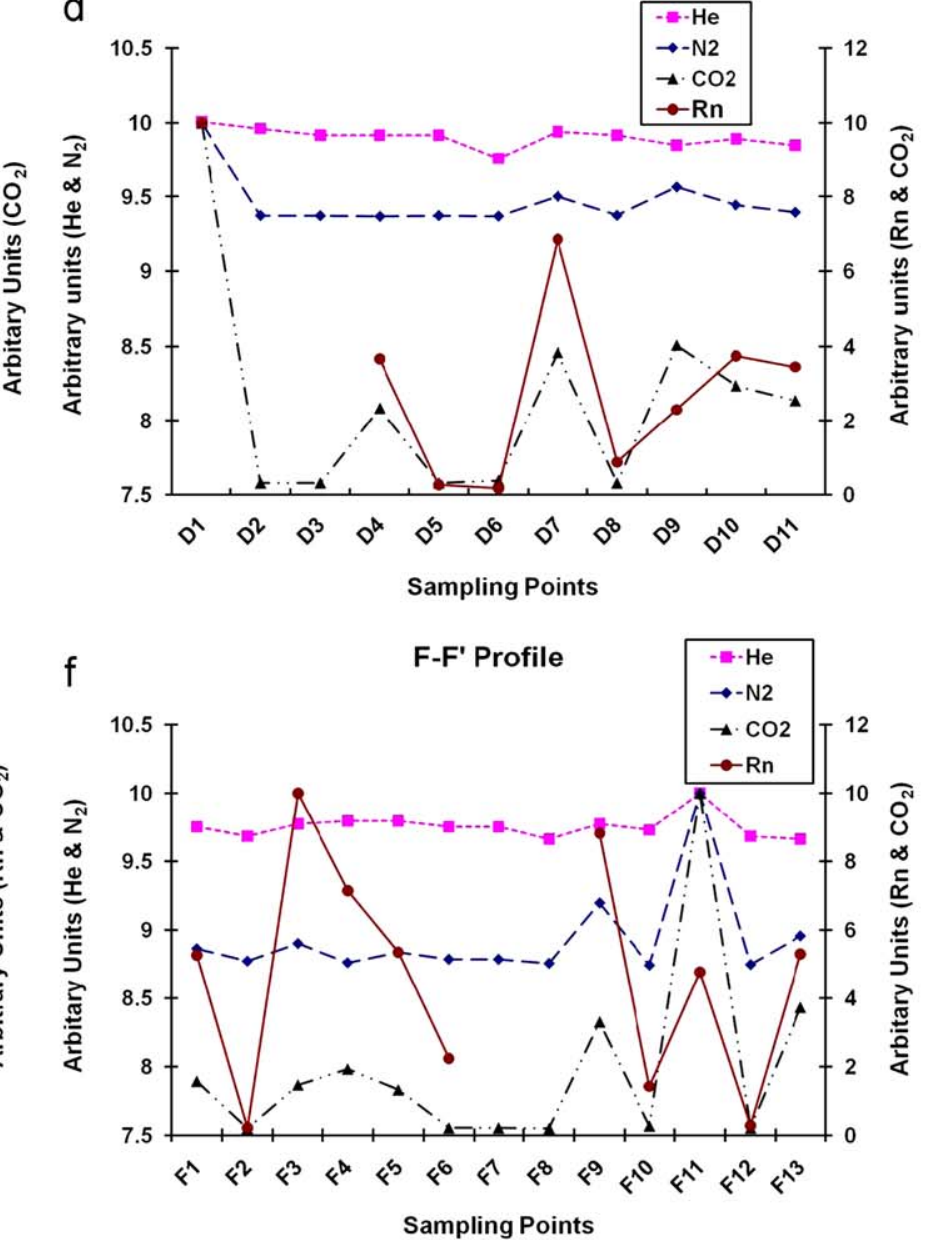

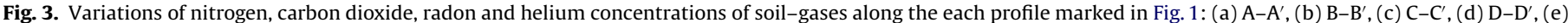

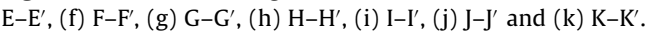


g

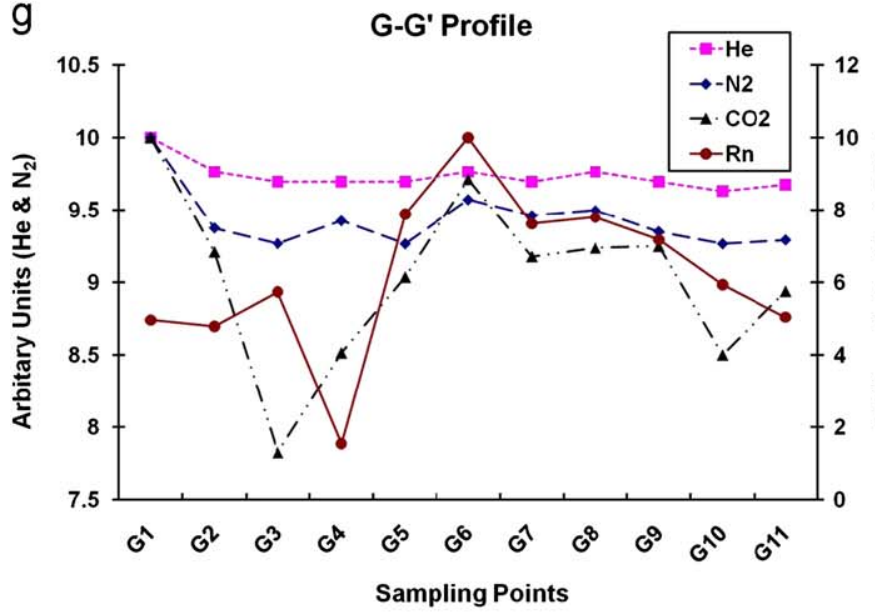

i

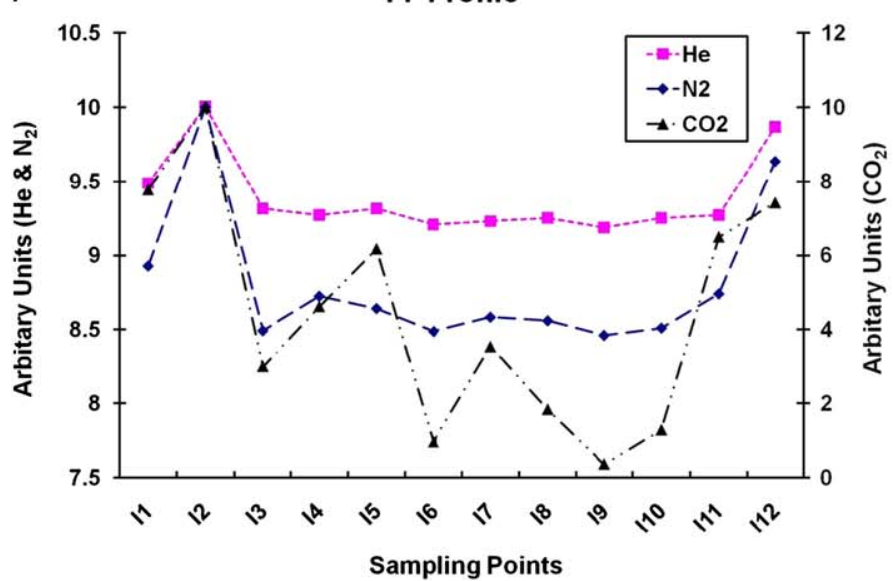

$\mathrm{h}$

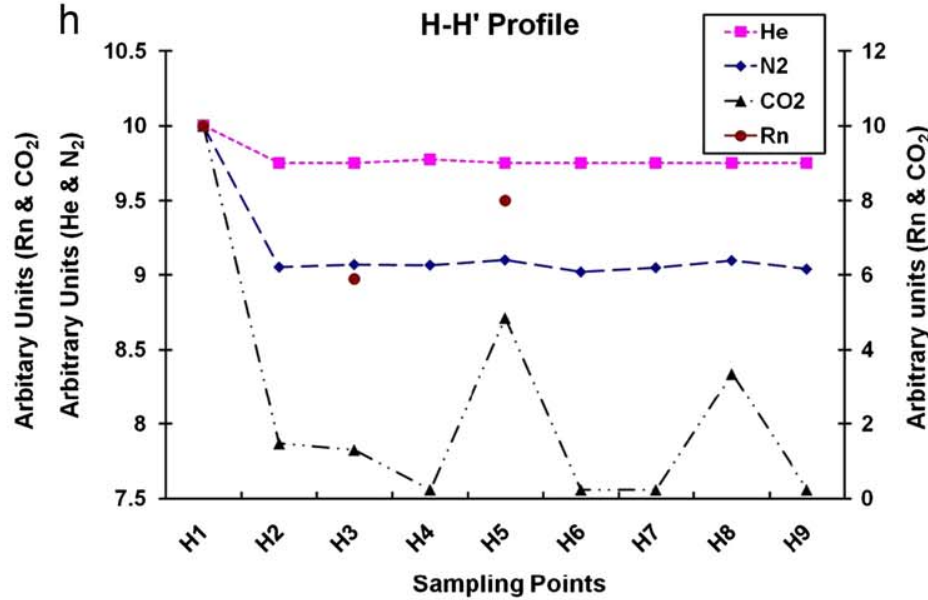

j

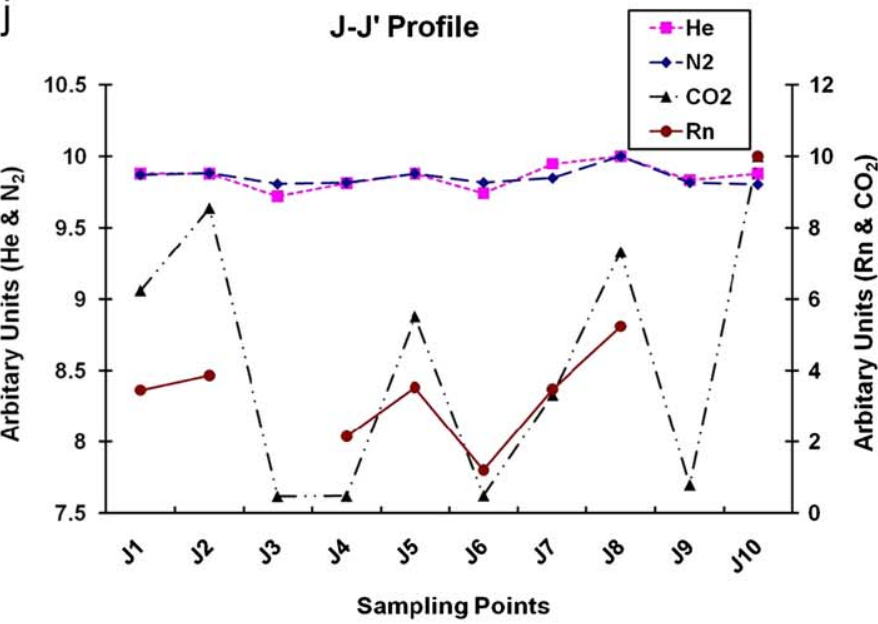

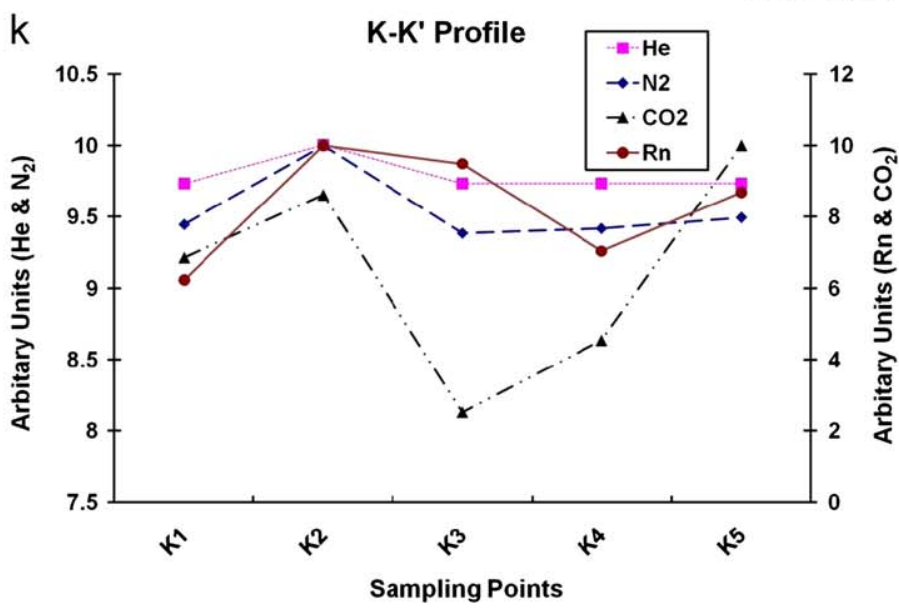

Fig. 3. (Continued)

$40.2 \pm 0.7 \mathrm{kBq} / \mathrm{m}^{3}$ at $\mathrm{E} 13$, the only values exceeding $40 \mathrm{kBq} / \mathrm{m}^{3}$ in the whole survey.

Distribution of data points for $\mathrm{N}_{2}, \mathrm{CO}_{2},{ }^{4} \mathrm{He}$ and ${ }^{222} \mathrm{Rn}$ measurements together with the identified anomalies along all the profiles crossing the Hsincheng fault, is shown in Fig. 4. Nitrogen and carbon dioxide have recorded maximum number of anomalies, i.e. 32 and 33, respectively (Fig. 4a and b). In the case of helium and radon the recorded anomalies numbered 28 and 16 respectively (Fig. 4c and d). Few numbers of anomalies of radon might be due to low number of sampling for radon, but the percentage anomalies in the case of radon and helium were about the same, i.e. 25\%. Nitrogen and carbon dioxide have slightly higher percentages of anomalies than radon and helium (i.e. $27 \%$ and $28 \%$ ), respectively. The higher percentages of nitrogen and carbon dioxide anomalies might possibly have originated from others sources (e.g. biogenic sources) (Hong et al., 2009). Most of the radon anomalies were found to be either on or nearby the Hsincheng fault or other tectonic structures, i.e. two anticlines and Hsinchu fault (Fig. 4d). Accordingly, more than $70 \%$ of helium anomalies were related to the aforementioned structures (i.e. Hsincheng and Hsinchu faults and Pao-Shan and Ching-Tsau-Hu anticlines) (Fig. 4c).

It can be established from previous studies (Baubron et al., 2002; Walia et al., 2005a; Fu et al., 2005; Etiope et al., 2005) that 


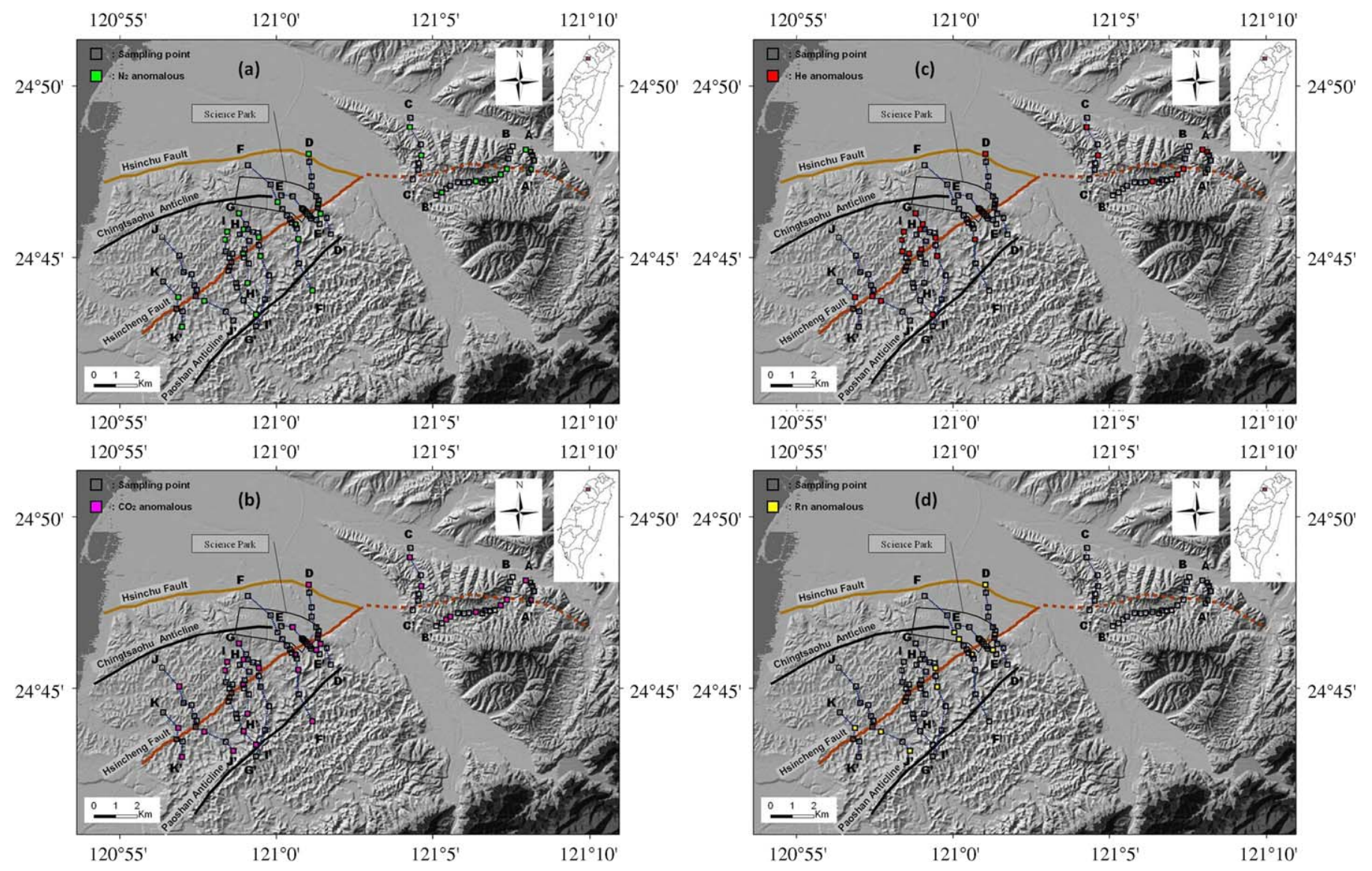

Fig. 4. Spatial distribution of soil-gas data points and anomalies (solid squares): (a) nitrogen, (b) carbon dioxide, (c) helium and (d) radon.

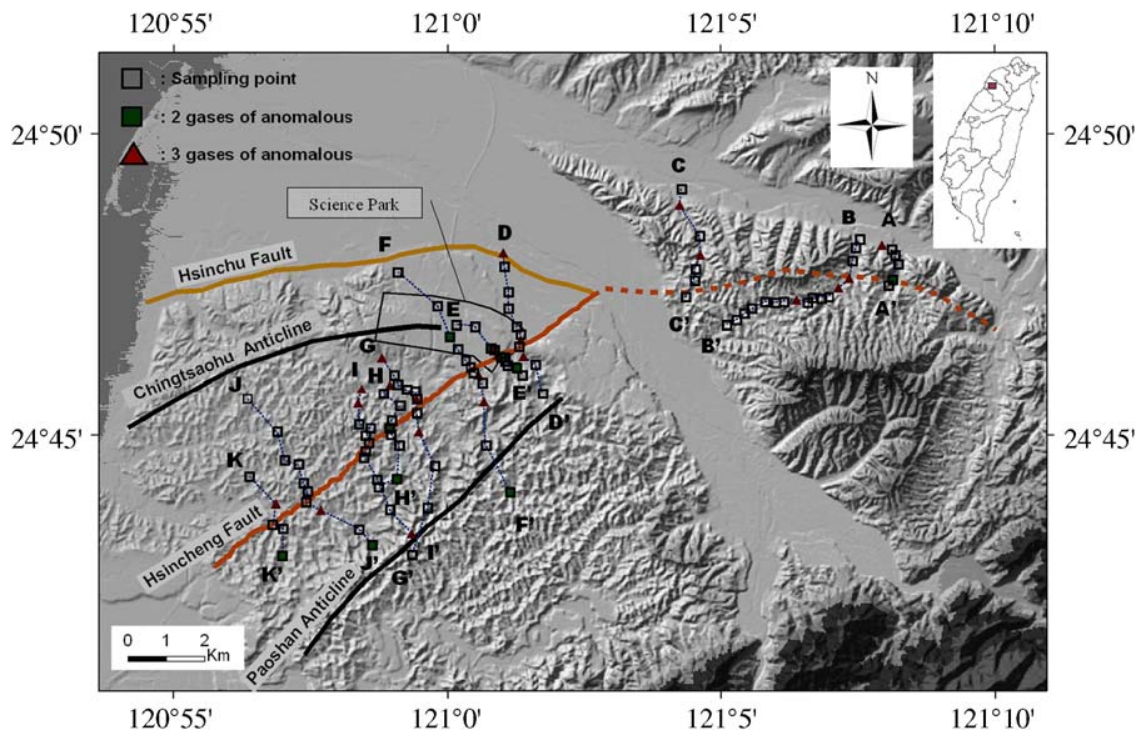

Fig. 5. Spatial distribution of soil-gas data points and co-existence of anomalous values in two or more gas species used for the analyses.

study of two or more than two gas species gives better results for fault delineation studies. In this study coexistence of anomalies in at least two or more than two gas species was considered and plotted in Fig. 5. Totally 34 points were recorded as coexisted anomalies (Fig. 5) and out of these about 65\% have shown anomalies for more than two gas species. Based on Fig. 5, the presence of more anomalies between Ching-Tsau-Hu anticline and
Hsincheng fault indicates that the area may have the large fault zone or/and some local fracturing. The analysis of profiles $A-A^{\prime}$, $B-B^{\prime}$ and $C-C^{\prime}$ and the presence of anomalies in more than two gas species indicates the presence of an extended fault zone represented by the dotted line (Fig. 5). The possible presence of an extension fault zone in the northeastern direction is evident from the analysis of profiles $A-A^{\prime}, B-B^{\prime}$ and $C-C^{\prime}$. 
Many studies have shown that the amount of helium is too low to form a macroscopic quantity of gas which can react to pressure gradient and flow autonomously by advection (in fault zones) to the surface (Kristiansson and Malmqvist, 1982; Etiope and Martinelli, 2002). For this advection movement, helium must be helped by the carrier gases (e.g. carbon dioxide, nitrogen, methane) or by carrier fluids to the surface. In the case of other noble gas radon, due to its short diffusion length, it cannot reach to the surface by its own and is usually carried by underground waters/fluids and also by carrier gases (Etiope and Lombardi,

Table 1

Correlation coefficient of noble gases with carrier gases.

\begin{tabular}{ll}
\hline Gas species & Correlation coefficient $\left(r^{2}\right)$ \\
\hline Helium-nitrogen & 0.83 \\
Helium-carbon dioxide & 0.31 \\
Radon-nitrogen & 0.27 \\
Radon-carbon dioxide & 0.40 \\
\hline
\end{tabular}

1995; Etiope et al., 2005; Yang et al., 2003) depending on the geological-hydrological settings. In the investigated area, the statistical correlation coefficient of $r=0.83$ between helium and nitrogen (Table 1) indicates that nitrogen might have acted as a carrier gas for helium. Carbon dioxide has shown poor correlation with helium having correlation coefficient of $r=0.31$, whereas it has shown somewhat better correlation with correlation coefficient of 0.40 with ${ }^{222} \mathrm{Rn}$ (Table 1 ). It indicates that carbon dioxide may be one of the potential carrier gases for radon in this area.

To understand the relationship between temporal variations of the soil concentration and seismic/crustal activity in this area, profile ' $E$ ' crossing the fault at the Hsinchu National Industrial Science Park (HNISP) (Fig. 6), was selected for continuous sampling. The location of this profile is close to the trench site where paleoseismic evidence confirmed that it is the surface trace of Hsincheng fault zone (Fig. 6). During the weekly monitoring high values of helium and carbon dioxide were recorded in between 1000 and $1500 \mathrm{~m}$ which may show presence of fault zone in that area (Fig. 6). Variation in both gas concentrations at each
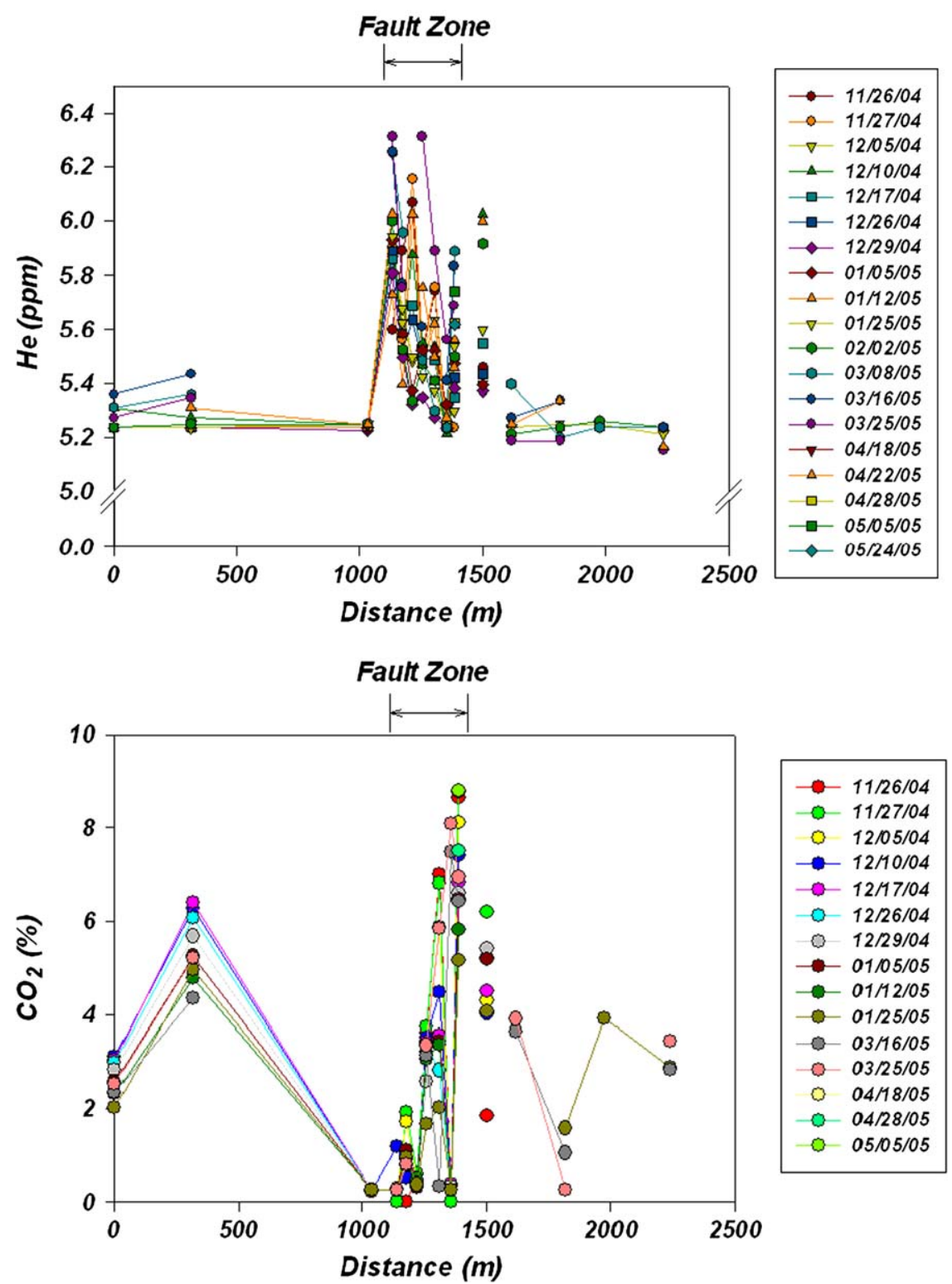

Fig. 6. Monitoring of soil-gas helium and carbon dioxide to identify the fault zone along profiles 'E' inside Hsinchu National Science Industrial Park (HNISP), Hisnchu. 
sampling point may be due to seasonal/meteorological or tectonic effects, but the overall trend along the profile remains the same.

Due to some technical and administrative reasons, we were forced to abandon the above profile for continuous weekly monitoring and so another profile in HNISP, near the old profile was selected for weekly monitoring. New profile was also located close to the above said trench site. After some weeks of continuous monitoring, these sampling points were reconstructed to reduce the meteorological effects and tested for some more weeks before selecting a point for final setup of monitoring station.

A continuous monitoring station was established in October 2005, using radon detectors RTM 2100 along with carbon dioxide detector. Continuous monitoring results (Fig. 7) have shown precursory signals for some impending earthquakes in the region (Table 2), but these results can be taken as preliminary and long term monitoring is needed to know more about the monitoring station's efficiency. An earthquake of $M_{L}=5.5$ having local intensity of 2 at the monitoring station on 30 November 2005 (marked 'a' in Fig. 7) with epicentral distance of $101 \mathrm{~km}$ from the monitoring station (Table 2 ) rocked the area. Although variation in radon concentration did not show remarkable increase, but thoron concentration has shown considerable increase which continued for almost two days, i.e. till 1 December before coming to normal values (Fig. 7). Similarly, an earthquake of $M_{L}=5.3$ having local intensity of 1 on 24 February 2006 (marked ' $c$ ' in Fig. 7) rocked almost all parts of Northern Taiwan. This seismic event recorded some precursory signals in radon variations. Radon content normally shows some variation around $40 \mathrm{kBq} /$ $\mathrm{m}^{3}$ but it started to increase on 22 February, and reached the value of about $50 \mathrm{kBq} / \mathrm{m}^{3}$ on 23 February, almost $22 \mathrm{~h}$ before the seismic event but thoron shows no any anomalies. These high values of radon continued for some period before reaching to its normal values on 28 February 2006. During the observation period, i.e. October 2005 to June 2006, seven earthquakes were recorded in the area. Among these earthquakes, two earthquakes of $M_{L}=4.8$ and 4.7 both having local intensity of 1 occurred on February 7 and March 29, 2006 (marked 'b' and 'd' in Fig. 7), respectively, and

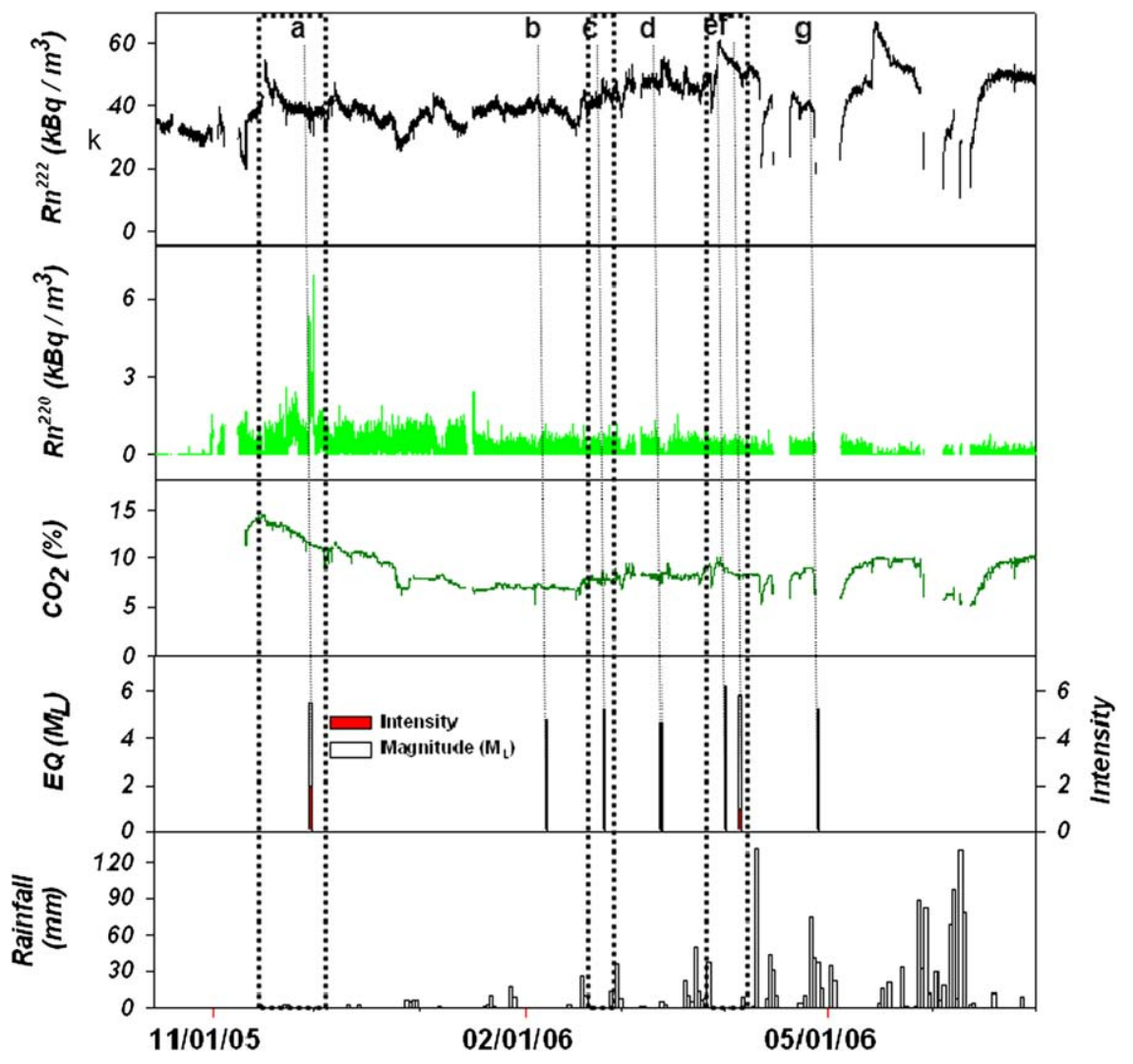

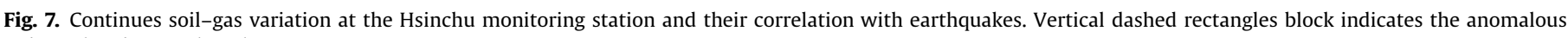
radon related to earthquakes.

Table 2

Catalog for the observed earthquakes at monitoring station from October 2005 to June 2006.

\begin{tabular}{|c|c|c|c|c|c|c|c|}
\hline No. $^{\mathrm{a}}$ & Date (mm/dd/yy) & Lat. $\left({ }^{\circ} \mathrm{N}\right)$ & Long. $\left({ }^{\circ} \mathrm{E}\right)$ & Depth $(\mathrm{km})$ & Mag. $\left(M_{L}\right)$ & Local intensity & Epicentral distance $(\mathrm{km})$ \\
\hline a & $11 / 30 / 2005$ & 24.7 & 122.03 & 68 & 5.5 & 2 & 101 \\
\hline b & $02 / 07 / 2006$ & 24.81 & 121.78 & 89.5 & 4.8 & 1 & 76 \\
\hline c & $02 / 24 / 2006$ & 24.78 & 122.78 & 48.5 & 5.2 & 1 & 122 \\
\hline d & 03/29/2006 & 26.62 & 121.08 & 70.5 & 4.7 & 1 & 206 \\
\hline $\mathrm{e}$ & $04 / 01 / 2006$ & 22.88 & 121.08 & 7.2 & 6.2 & 2 & 209 \\
\hline $\mathrm{f}$ & $04 / 05 / 2006$ & 24.49 & 122.76 & 99.5 & 5.8 & 1 & 178 \\
\hline $\mathrm{g}$ & $04 / 28 / 2006$ & 23.99 & 121.61 & 9.8 & 5.2 & 1 & 105 \\
\hline
\end{tabular}

${ }^{\text {a }}$ As per numbers marked in Fig. 7. 
did not show any sign in terms of soil-gas data. Both the events had a focal depth of over $70 \mathrm{~km}$ and thus might not have disturbed the degassing system in the region due to their great depths. On the other hand, during mid April and thereafter heavy rains were recorded in the area, leading the water percolation down into soil distribution the degassing system at the monitoring station. But, during the observation period from October 2005 till mid-April 2006, monitoring station was not disturbed by moderate rains.

\section{Conclusions}

On the basis of obtained results, it can be concluded that the soil ${ }^{4} \mathrm{He},{ }^{222} \mathrm{Rn}, \mathrm{CO}_{2}$ and $\mathrm{N}_{2}$ gas anomaly patterns observations can provide useful information to identify fault location of Hsincheng fault along with its extension (shown by dashed line in Fig. 4) and help us to locate the other tectonic structures in study area. From the spatial distribution of the soil gas anomalies results, it can be concluded that monitoring of two or more than two gas species gives more reliable information. Soil-gas data give us some evidences to understand the tectonic setting of an area. The presence of two active faults at short span of distance creates a zone of small parallel faults in the region which is indicated by the spatial distribution of soil-gas data. Faults can be described as least-strength zones composed of highly fractured materials and show easy gas migration towards the surface. Further, statistical correlation analysis of soil-gas species used indicates that the nitrogen may be the major carrier gas for the helium in the region.

In order to select the best site for continuous monitoring, the occurrence of deeper gas emanations from the ground was investigated by the soil-gas survey. Further, the continuous weekly monitoring along the fixed profile could be helpful to find fault zone and to select site for long term continuous monitoring. The selection of site for continuous monitoring was made on the basis of high concentration of radon and helium, together with excess of carrier gases viz. nitrogen and carbon dioxide. Obtained data from the continuous monitoring station and their correlations with some earthquakes during the observation period reveal that tectonic activity may disturb the degassing system and the selected site may be sensitive to stress variations. From the results of present study it is evident that the soil-gas method appears as a suitable tool for studying spatial and temporal gas variations in fault zones to find the fault trace and also for earthquake precursory studies along the Hsincheng fault, Hsinchu area of NW Taiwan.

\section{Acknowledgements}

The authors acknowledge the National Science Council of Taiwan for providing all the financial support. We are thankful to Mr. K.W. Wu for his help in sample collecting and analysis.

\section{References}

Al-Taminmi, M.H., Abumurad, K.M., 2001. Radon anomalies along faults in North of Jordan. Radiat. Meas. 34, 397-400.

Banwell, G.M. Parizek, R.R., 1988. Helium-4 and radon-222 concentrations in groundwater and soil-gas as indicator of fault zones of fracture concentration in unexposed rock. J. Geophys. Res. 93, B1.

Baubron, J.C., Allard, P., Toutain, J.P., 1990. Diffuse volcanic emissions of carbon dioxide from Vulcano Island Italy. Nature 344, 51-53.

Baubron, J.C., Allard, P., Sabroux, J.C., Tedesco, D., Toutain, J.P., 1991. Soil-gas emanations as precursory indicators of volcanic eruptions. J. Geol. Soc. London 148, 571-576.

Baubron, J.C., Rigo, A., Toutain, J.P., 2002. Soil gas profiles as a tool to characterize active tectonic areas: the Jaut Pass example (Pyrenees, France). Earth Planet Sci. Lett. 196, 69-81.
Ciotoli, G., Guerra, M., Lombardi, E., Vittori, E., 1998. Soil-gas survey for tracing seismogenic faults: a case study in the Fucino basin, Central Italy. J. Geophys. Res. 103, 23781-23794.

Etiope, G., Lombardi, S., 1995. Evidence for radon transport by carrier gas through faulted clays in Italy. J. Radioanal. Nucl. Chem. 193 (2), 291-300.

Etiope, G., Martinelli, G., 2002. Migration of carrier and trace gases in the geosphere: an overview. Phys. Earth Planet. Inter. 129, 185-204.

Etiope, G., Guerra, M., Raschi, A., 2005. Carbon dioxide and radon geohazards over a gasbearing fault in the Siena Graben (Central Italy). Terr. Atmos. Oceanic Sci. $16,885-896$.

Fu, C.C., Yang, T.F., Walia, V., Chen, C.-H., 2005. Reconnaissance of soil-gas composition over the buried fault and fracture zone in Southern Taiwan. Geochem. J. 39, 427-439.

Fu, C.C., Yang, T.F., Jane, D., Liu, T.K., Walia, V., Chen, C.-H., 2008. Variations of helium and radon concentrations in soil gases from an active fault zone in Southern Taiwan. Radiat. Meas. 43, S348-S352.

Guerra, M., Lombardi, S., 2001. Soil-gas method for tracing neotectonic faults in clay basins: the Pisticci field (Southern Italy). Tectonophysics 339, 511-522.

Heinicke, J., Martinelli, G., Koch, U., 1992. Investigation of the connection between seismicity and $\mathrm{CO}_{2}-{ }^{222} \mathrm{Rn}$ content in spring water at the Vogtland area (Germany): first results. In: Abstract, XXIII General Assembly of the European Seismological Commission, Prague.

Hong, W.L., Yang, T.F., Walia, V., Lin, S.J., Fu, C.C., Chen, C.-H, Wen, K.L., 2009 Evidences support nitrogen as carrier gas of helium along Hsincheng fault, NW Taiwan. Appl. Geochem., accepted for publication.

Irwin, W.P., Barnes, I., 1980. Tectonic relations of carbon dioxide discharges and earthquakes. J. Geophys. Res. 85, 3115-3121.

Klusman, R.W., 1993. Soil-gas and Related Methods for Natural Resource Exploration. Wiley, Chichester 483pp.

Kristiansson, K., Malmqvist, L., 1982. Evidence for non-diffusive transport of 222Rn the ground and a new physical model for the transport. Geophysics 47, 1444-1452.

Lepeltier, C., 1969. A simplified statistical treatment of geochemical data by graphical representation. Econ. Geol. 64, 538-550.

Lin, C.-W., Chang, H.-C., Lu, S.-T., Shih, T.-S., Huang, W.-J., 2000. An Introduction to the Active Faults of Taiwan. Explanatory Text of the Active Fault Map of Taiwan (in Chinese with English abstract), second ed. Spec. Publ. Cent. Geol. Surv. vol. 13, Taipei, Taiwan, 122pp.

Pinault, J.L., Baubron, J.C., 1997. Signal processing diurnal and semidiurnal variations in radon and atmospheric pressure: a new tool for accurate in-situ measurements of soil-gas velocity, pressure gradient and tortuosity. J. Geophys. Res. 102, 18101-18120.

Rahn, T.A., Fessenden, J.E., Wahlen, M., 1996. Flux chamber measurements of anomalous $\mathrm{CO}_{2}$ emission from the flanks of Mammoth Mountain, California. Geophys. Res. Lett. 23, 1861-1864.

Roberts, A.A., Friedman, I., Donovan, T.J., Denton, E.H., 1975. Helium survey, a possible technique for locating geothermal reservoirs. Geophys. Res. Lett. 2, 209-210.

Shapiro, M.H., Melvin, J.D., Tombrello, T.A., Fong-Liang, J., Gui-Ru, L., Mendenhall, M.H., Rice, A., 1982. Correlated radon and $\mathrm{CO}_{2}$ variations near the San-Andreas fault. Geophys. Res. Lett. 9, 503-506.

Shih, R.C., 1999. Geophysical prospecting of active faults in Northern Taiwan. Project Report to the Central Geological Survey, MOEA.

Sugisaki, R., Anno, H., Aedachi, M., Ui, H., 1980. Geochemical features of gases and rocks along active faults. Geochem. J. 14, 101-112.

Sugisaki, R., Ido, M., Takeda, H., Isobe, Y., Hayashi, Y., Nakamura, N., Satake, H., Mizutani, Y., 1983. Origin of hydrogen and carbon dioxide in fault gases and its relation to fault activity. J. Geol. 91, 239-258.

Toutain, J.-P., Baubron, J.C., 1999. Gas geochemistry and seismotectonics: a review. Tectonophysics 304, 1-27.

Toutain, J.P., Baubron, J.C., Le Bronec, J., Allard, P., Briole, P., Marty, B., Miele, G., Tedesco, D., Luongo, G., 1992. Continuous monitoring of distal gas emanations at Vulcano, Southern Italy. Bull. Volcanol. 54, 147-155.

Virk, H.S., Walia, V., Kumar, N., 2001. Radon/helium precursory signals of Chamoli earthquakes, Garhwal Himalaya, India. J. Geodyn. 31, 201-210.

Walia, V., Mahajan, S., Kumar, A., Singh, S., Bajwa, B.S., Yang, T.F., 2008. Fault delineation study using soil-gas method in Dharamsala area, NW Himalayas, India. Radiat. Meas. 43, S337-S342.

Walia, V., Su, T.C., Fu, C.C., Yang, T.F., 2005a. Spatial variations of radon and helium concentration in soil-gas across Shan-Chiao fault, Northern Taiwan. Radiat. Meas. 40, 513-516.

Walia, V., Virk, H.S., Yang, T.F., Mahajan, S., Walia, M., Bajwa, B.S., 2005b. Earthquake prediction studies using radon as a precursor in N-W Himalayas, India: a case study. Terr. Atmos. Oceanic Sci. 16 (4), 775-804.

Walia, V., Virk, H.S., Bajwa, B.S., 2006. Radon precursory signals for some earthquakes of magnitude $>5$ occurred in N-W Himalaya. Pure Appl. Geophys. $163,711-721$.

Yang, T.F., Chou, C.Y., Chen, C.-H., Chyi, L.L., Jiang, J.H., 2003. Exhalation of radon and its carrier gases in SW Taiwan. Radiat. Meas. 36, 425-429.

Yang, T.F., Walia, V., Chyi, L.L., Fu, C.C., Chen, C.-H., Liu, T.K., Song, S.R., Lee, C.Y., Lee, M., 2005. Variations of soil radon and thoron concentrations in a fault zone and prospective earthquakes in SW Taiwan. Radiat. Meas. 40, 496-502.

Yang, T.F., Fu, C.C., Walia, V., Chen, C.-H., Chyi, L.L., Liu, T.K., Song, S.R., Lee, M., Lin, C.W., Lin, C.C., 2006. Seismo-geochemical variations in SW Taiwan: multiparameter automatic gas monitoring results. Pure Appl. Geophys. 163, 693-709. 